\title{
FORMULATION AND IN-VITRO \\ CHARACTERIZATION OF ABACAVIR SULPHATE \\ EFFERVESCENT FLOATING TABLETS
}

\author{
Nihari Thatikonda ${ }^{1}$, Sree Giri Prasad Beri ${ }^{2}$, Krishna Mohan Chinnala ${ }^{3}$, \\ Aravinda Nalla ${ }^{* 4}$
}

School of Pharmacy, Department of Pharmaceutics, Nalla Narasimha Reddy Education

Society's Group of Institutions, Hyderabad, Telangana, India.

nihari.niha1195@gmail.com, prasad.bsreegiri@gmail.com, drchinnala@gmail.com,

aravindhanalla@gmail.com

\section{*Corresponding Author: \\ ARAVINDA NALLA,}

Assistant Professor, Department of Pharmaceutics,

Nalla Narasimha Reddy Education Society's Group of Institutions,

Chowdariguda (V), Ghatkesar (M), Medchal (D), Telangana, India 500088.

E-mail: aravindhanalla@gmail.com

\begin{abstract}
After oral administration of Abacavir, rapid absorption occurs from upper part of gastro intestinal tract with peak concentrations occurring at $0.63-1 \mathrm{hr}$ after dosing. Conventional drug therapy with tablets produce relatively rapid and high peak blood levels that requires frequent administration to maintain effective range of plasma drug levels. This conventional therapy leads to reduced effectiveness with poor therapeutic management. To overcome the inadequacy of conventional therapy with tablets, floating sustained release Abacavir tablets were developed. Floating sustained release Abacavir Sulphate tablets were prepared by using direct compression method. Tablet were formulated using Ethyl Cellulose with hydrocolloids like Hydroxypropyl Methylcellulose (HPMC K4M) and Carbopol 974P as release retarding polymers, Sodium bicarbonate $\left(\mathrm{NaHCO}_{3}\right)$ and Citric acid as effervescent agents. Tablets were then evaluated for various physical parameters including hardness, thickness, weight variation, friability, drug content, in-vitro buoyancy, Swelling index and Invitro gastro retentive drug release were conducted. Drug and excipient compatibility studies show that they are compatible with each other. The optimized formulation (F9) shows the hardness of $5.7 \mathrm{~kg} / \mathrm{cm}^{2}$, tablet thickness of $2.74 \mathrm{~mm}, 0.45 \%$ of friability, in-vitro buoyancy was up to 6 hours and \% drug release was $90.56 \%$ in 6 hours. Drug release kinetics was found to follow non-fickian diffusion. Hence, F9 is considered as optimized formulation based on invitro buoyancy and \% drug release.
\end{abstract}

Keywords: Abacavir sulphate; Carbopol 974P; HPMC K4M; Ethyl cellulose; Effervescent floating tablets. 


\section{INTRODUCTION}

Different types of gastro-retentive dosage forms have been created over the past two centuries to prolong gastric residence time. The type of dosage form allows direct administration of drugs with a narrow absorption opening at the apex of the gastrointestinal tract or drug with low colon stabilization. The drug can also act locally within the stomach and extended intimate contact with the absorbing membrane which increases effectiveness ${ }^{[1-}$ ${ }^{2]}$. Floating drug delivery systems have a lower bulk density than gastric fluids and therefore remain in the stomach for an extended period of time, without affecting the rate of gastric emptying. The drug is released slowly from the system at the desired rate while the system is floating on the gastric contents ${ }^{[3-4]}$. The residual system is emptied from the stomach following the release of the drug. This leads to an increase in gastro retentive time (GRT) and better control of plasma drug concentration fluctuations. It is possible to classify floating systems into two distinct categories: non-effervescent and effervescent ${ }^{[5]}$.

Acquired immune deficiency syndrome (AIDS), is a threatening disease in present generation. Actually, AIDS is not a disease but it is a collection of 70 or more circumstances that arise from the human immunodeficiency virus (HIV) infection to the immune system and other areas of the body. It is essential that the systematic drug concentration in the treatment is constantly greater than that for AIDS therapy ${ }^{[6]}$. There are also a number of drugs that are regarded as anti-HIV. Abacavir sulphate is an antiretroviral HIV reverse transcriptase nucleoside inhibitor. Antiretroviral agents, nucleoside inhibitors are used in the treatment of relatively short half-life plasma drugs, are routinely administered alone or with other antiretroviral. The treatment of patients with relatively short plasma half-life is common. This study thus formulated effervescent floating tablets of Abacavir sulphate with the use of hydrocolloids to delay the release of $\operatorname{drug}^{[7]}$.

\section{MATERIALS AND METHODS MATERIALS}

Abacavir sulphate was given as gift sample by KP Labs, Hyderabad. Carbopol 974P, HPMC K4M and Ethyl cellulose was obtained from MerckSpecialities Pvt Ltd, Mumbai, sodium bicarbonate, citric acid, microcrystalline cellulose, talc and magnesium stearate was obtained from SD-Fine Chemicals, Mumbai.

\section{METHODS}

Analytical Method Development: The UV Spectrophotometric method was selected for the estimation of Abacavir sulphate. $20 \mu \mathrm{g} / \mathrm{ml}$ concentration of drug was chosen and absorbance was measured in between the range of $200-400 \mathrm{~nm}$.

\section{Drug-Excipient incompatibility studies \\ Fourier transform infrared (FT-IR) spectroscopy}

Drug and excipient compatibility were studied by FT-IR spectroscopy of API with various excipients used in the formulation. 


\section{Differential scanning calorimetry (DSC)}

$1 \mathrm{mg}$ of API Abacavir sulphate and effervescent floating tablets were sealed in aluminium pans for DSC scanning. It is carried out to find out the presence of any interaction among drug and the excipients. The various samples along with optimized batch were checked for DSC study ${ }^{[8-9]}$.

\section{Formulation of effervescent floating tablets of Abacavir sulphate}

The tablets were prepared by direct compression technique. The compositions of all formulations were given in the Table 1 . All the ingredients were accurately weighed and passed through sieves accordingly. Then except, magnesium stearate all other ingredients were blended uniformly in mortar and pestle. After enough mixing of drug and other components, magnesium stearate was added as lubricant and further mixed for 2-3 minutes. Blended powder mixture was then punched by means of rotary tablet compression machine.

\section{Characterization of powder blend}

The flow properties of blend were characterized in terms of angle of repose, bulk density, tapped density, Carr's index, and Hausner's ratio. For determination of angle of repose, the powder blend was poured through the walls of a funnel, which was fixed at a position such that its lower tip was at a height of exactly $2 \mathrm{~cm}$ above hard surface. The formulas are given below:

$$
\text { Angle of repose: } \tan \theta=\frac{h}{x} \text { (or) } \theta=\tan ^{-1} \frac{h}{r}
$$

Where,

$\theta=$ angle of repose,

$\mathrm{h}=$ height,

$\mathrm{r}=$ radius.

$$
\text { Bulk density: } B . D=\frac{M}{v_{0}}
$$

Where,

$\mathrm{M}=$ mass of the powder,

$\mathrm{V}_{0}=$ bulk volume of the powder.

$$
\text { Tapped density: } T \cdot D=\frac{M}{V_{t}}
$$

Where,

$\mathrm{M}=$ mass of the powder,

$\mathrm{V}_{\mathrm{t}}=$ final tapped volume of the powder.

$$
\begin{gathered}
\text { Compressibility Index:C.I }=\frac{(\text { Tapped density }- \text { Bullk density }) \mathrm{X} 100}{\text { Tapped density }} \\
\text { Hausner's Ratio:H.R }=\frac{\text { Tapped density }}{\text { Bulk density }}
\end{gathered}
$$

\section{Characterization of Abacavir sulphate effervescent floating tablets}

The prepared tablets were evaluated for thickness using Vernier caliper, uniformity of weight using Shimadzu sensitive balance, hardness using Monsanto tester and friability using Sisco friability tester. 


\section{Weight variation $=\frac{\text { Average weight of tablet-individual weight of tablet }}{\text { average weight of tablet }} \times 100$}

Friability: $\% F=\left[1-\left(\frac{W_{0}}{W}\right)\right] \times 100$

Where,

$\% \mathrm{~F}=$ friability in percentage,

$\mathrm{W}_{0}=$ initial weight of tablet,

$\mathrm{W}=$ final weight of tablet.

\section{Drug Content}

Tablets were taken, powdered and the powder equivalent to one dose each was transferred to a $100 \mathrm{ml}$ volumetric flask and $0.1 \mathrm{~N} \mathrm{HCl} \mathrm{pH} 1.2$ was added. The volume was then made up to the mark with $0.1 \mathrm{~N} \mathrm{HCl} \mathrm{pH} \mathrm{1.2.} \mathrm{The} \mathrm{solution} \mathrm{was} \mathrm{filtered} \mathrm{and} \mathrm{diluted}$ suitably and drug content in the samples was estimated using UV-spectrophotometer at 256 $\mathrm{nm}$.

\section{In-Vitro Buoyancy Studies}

The samples were placed in a $100 \mathrm{ml}$ beaker containing $0.1 \mathrm{~N} \mathrm{HCl} \mathrm{pH} 1.2$. The time required for the tablet to rise to the surface and float was determined as floating lag time ${ }^{[10-}$ 11]. The duration of time for which the dosage form constantly remained on the surface of medium was determined as the total floating time.

\section{Swelling Index}

The swelling index of tablets was determined in $0.1 \mathrm{~N} \mathrm{HCl} \mathrm{pH} 1.2$ at room temperature. The swollen weights of the tablets were determined after predetermined time intervals. The swelling index was calculated by the equation given below:

Swelling index, $\mathbf{S} . \mathbf{I}=\frac{\left(\mathrm{w}_{\mathrm{t}}-\mathrm{w}_{0}\right) \times 100}{\mathrm{w}_{0}}$

Where,

$\mathrm{W}_{\mathrm{t}}=$ weight of the tablet at time $\mathrm{t}$.

$\mathrm{W}_{0}=$ initial weight of tablet.

\section{In-Vitro drug release studies}

The in-vitro drug release study was performed for the Abacavir sulphate effervescent floating tablets using USP Type II (paddle method, lab India). The dissolution test was performed using $900 \mathrm{ml}$ of $0.1 \mathrm{~N}$ hydrochloric acid at $37 \pm 0.5^{\circ} \mathrm{C}$ and $50 \mathrm{rpm}$. A sample $(5 \mathrm{ml})$ of the solution was withdrawn from the dissolution apparatus hourly and the samples were replaced with fresh dissolution medium.

\section{Drug Release Kinetics}

In order to examine the release mechanism of Abacavir sulphate from the prepared effervescent floating tablets of the optimized formulation (F9), the results of the dissolution study were examined in kinetic models. The regression coefficient $\mathrm{R}^{2}$ value nearer to 1 indicated the model fitting of the release mechanism. 


\section{RESULTS AND DISCUSSION}

\section{Analytical Method Development}

Abacavir sulphate showed absorption maxima at $256 \mathrm{~nm}$ in $0.1 \mathrm{~N} \mathrm{HCl}$ of $\mathrm{pH} 1.2$ (fig 1) by UV Spectrophotometric method.

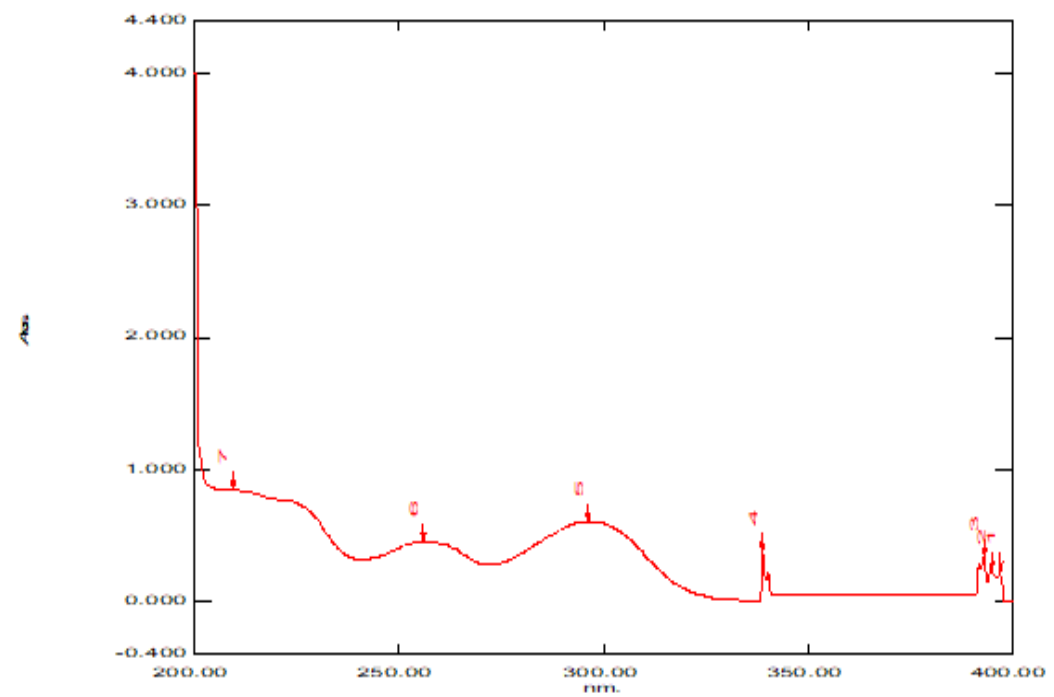

Fig - 1: UV-Spectrum of Abacavir Sulphate

\section{Preparation of stock and working standard solutions}

$100 \mathrm{mg}$ of Abacavir sulphate was accurately weighed and transferred into a $100 \mathrm{ml}$ volumetric flask, dissolve the drug in suitable volume of $0.1 \mathrm{~N} \mathrm{HCl} \mathrm{of} \mathrm{pH} 1.2$. Then, further diluted the above solution up to the mark with $0.1 \mathrm{~N} \mathrm{HCl} \mathrm{pH} 1.2$ to obtain the drug concentration of $1000 \mu \mathrm{g} / \mathrm{ml}$. From this solution, $10 \mathrm{ml}$ was further diluted using same solvent to obtain drug concentration of $100 \mu \mathrm{g} / \mathrm{ml}$ as a working standard solution.

\section{Preparation of Calibration Curve in $0.1 \mathrm{~N} \mathrm{HCl} \mathrm{of} \mathrm{pH} 1.2$}

Appropriate dilutions were made from stock solution to obtain solutions of 10, 20, 30 and $40 \mu \mathrm{g} / \mathrm{mlconcentrations.} \mathrm{Samples} \mathrm{were} \mathrm{analyzed} \mathrm{under} \mathrm{the} \mathrm{absorbance} \mathrm{maxima} \mathrm{of} 256 \mathrm{~nm}$. The standard curve was plotted between areas under curve values against concentrations and the results were shown in the below fig 2.

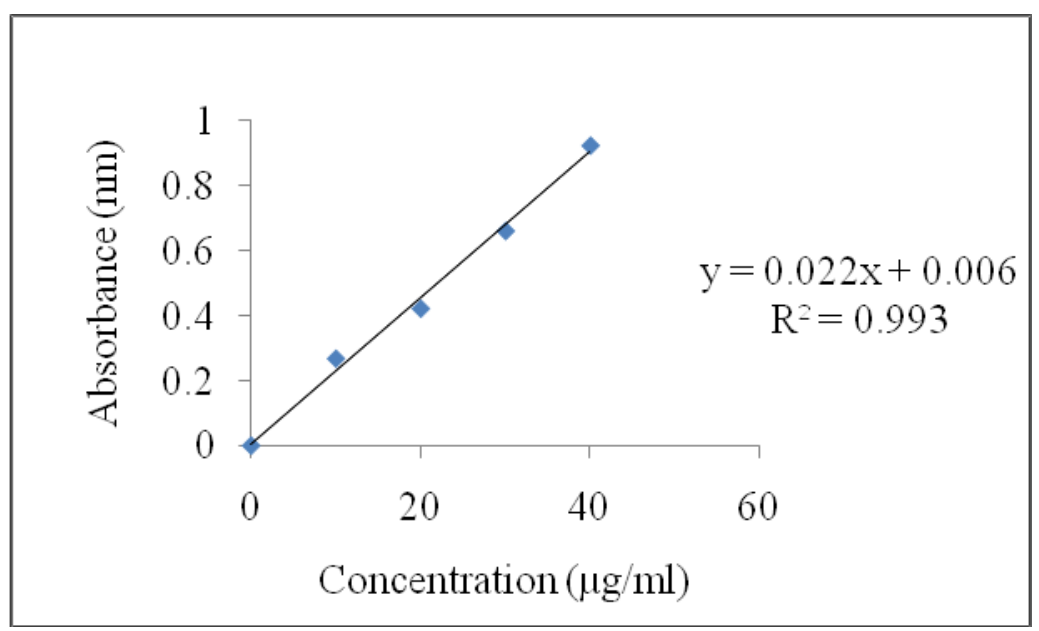

Fig - 2: Standard Calibration Curve of Abacavir Sulphate in $0.1 \mathrm{~N} \mathrm{HCl}$ 


\section{Drug-Excipient incompatibility studies}

\section{Fourier transformed infrared (FT-IR) spectroscopy}

The FT-IR spectra result (fig3) indicated that there was no drug-excipient interaction. The IR spectra recorded for the API Abacavir sulphate and the optimized formulation showed peaks at $3286 \mathrm{~cm}^{-1}$ (O-H stretching),2920 $\mathrm{cm}^{-1} \quad\left(-\mathrm{CH}_{2}\right.$ stretching $)$ and $1678 \mathrm{~cm}^{-1}(\mathrm{C}=\mathrm{N}$ stretching). In the formulation, peaks were observed at 3282, 2918 and $1678 \mathrm{~cm}^{-}{ }^{1}$ was.From the compatibility studies it was observed that the functional groups whichare present in API as well in the optimized formulation are having very negligible changes of peaks, this clearly indicates that the drug and excipients have no interactions.

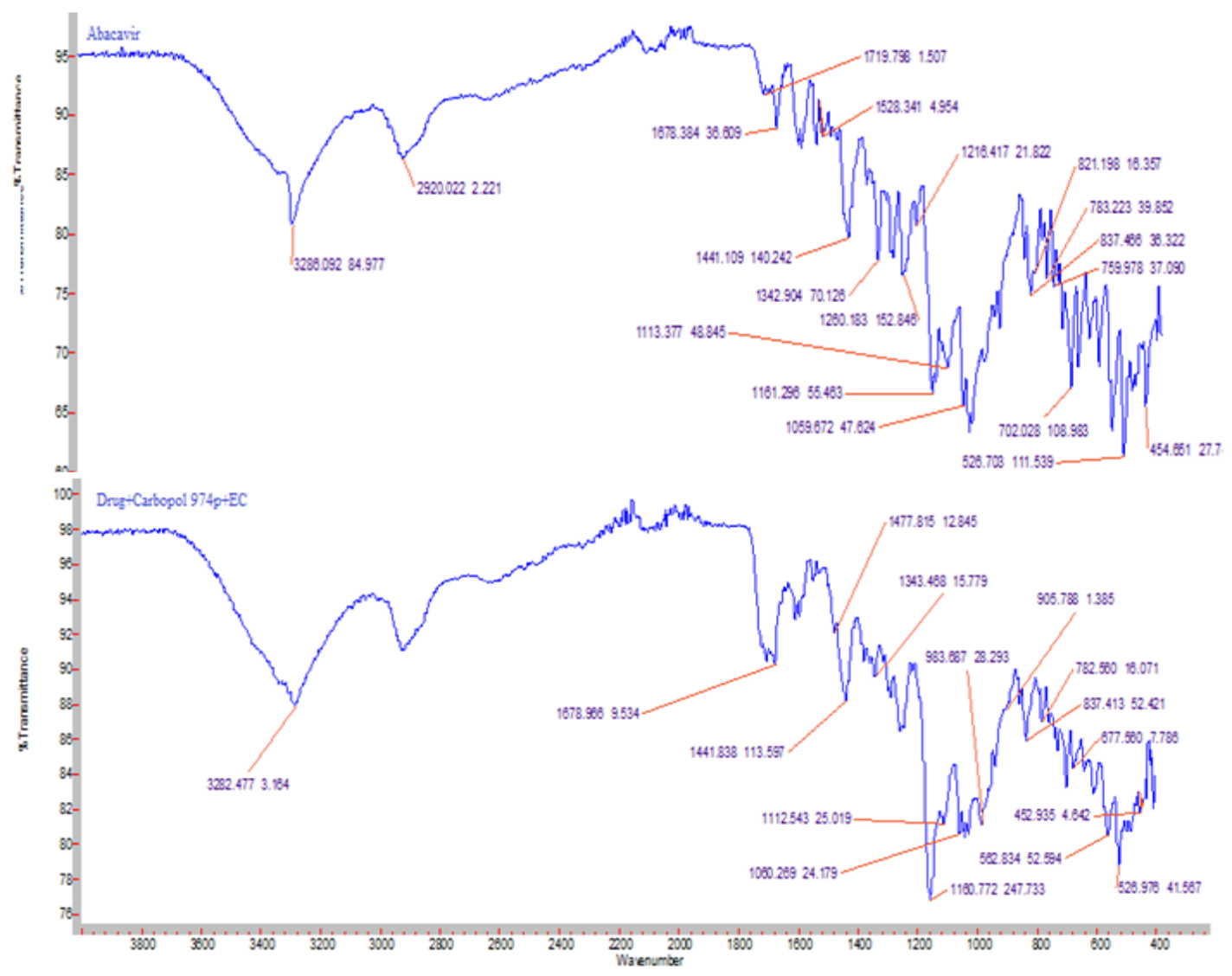

Fig - 3: FT-IR of Abacavir Sulphate and optimized formulation F9

\section{Differential scanning calorimetry}

DSC was performed for Abacavir sulphate and optimized formulation i.e. F9 which is represented in fig - 4. The DSC thermo gram of Abacavir sulphate displayed a characteristic peak at $225.8^{\circ} \mathrm{C}$. The formulation F9 (Abacavir sulphate + Carbopol 974P + Ethyl Cellulose) exhibits a sharp peak at $226.3^{\circ} \mathrm{C}$. Hence, DSC study shows that there is no drug polymer interaction. 


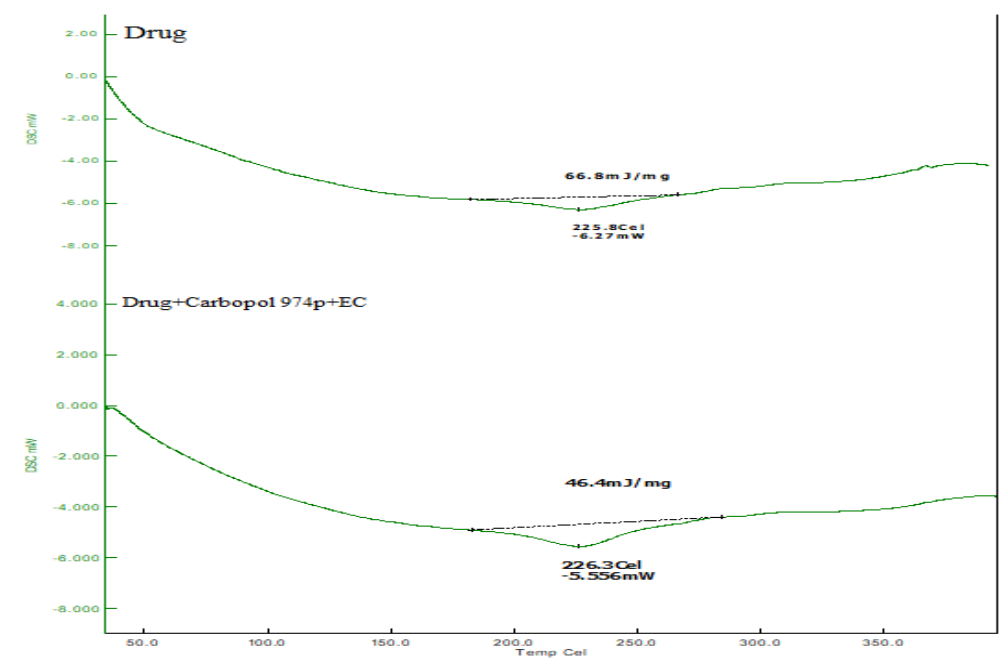

Fig - 4: DSC of API and optimized formulation F9

Table - 1: Composition of Abacavir sulphate effervescent floating tablets

\begin{tabular}{|c|c|c|c|c|c|c|c|c|c|}
\hline $\begin{array}{l}\text { Ingredients } \\
\text { (mg/tablet) }\end{array}$ & F1 & F2 & F3 & F4 & F5 & F6 & F7 & F8 & F9 \\
\hline Abacavir sulphate & 150 & 150 & 150 & 150 & 150 & 150 & 150 & 150 & 150 \\
\hline Carbopol974P & 15 & - & - & 30 & - & - & 7.5 & - & 15 \\
\hline HPMC K4M & - & 15 & - & - & 30 & 7.5 & - & 15 & - \\
\hline Ethyl cellulose & - & - & 7.5 & - & - & 7.5 & 7.5 & 15 & 15 \\
\hline $\begin{array}{l}\text { Micro crystalline } \\
\text { cellulose }\end{array}$ & 95 & 95 & 102.5 & 80 & 80 & 95 & 95 & 80 & 80 \\
\hline $\begin{array}{l}\text { Sodium } \\
\text { bicarbonate }\end{array}$ & 30 & 30 & 30 & 30 & 30 & 30 & 30 & 30 & 30 \\
\hline Citric acid & 4 & 4 & 4 & 4 & 4 & 4 & 4 & 4 & 4 \\
\hline $\begin{array}{l}\text { Magnesium } \\
\text { stearate }\end{array}$ & 2 & 2 & 2 & 2 & 2 & 2 & 2 & 2 & 2 \\
\hline Talc & 4 & 4 & 4 & 4 & 4 & 4 & 4 & 4 & 4 \\
\hline
\end{tabular}

HPMC = Hydroxy propyl methylcellulose.

\section{Characterization of powder blend}

The flow properties of powder blend have evaluated and the results are shown below in Table - 2. Inter-particle interactions that influence the bulking properties of a powder flow. A comparison of a bulk density and tapped density can give a measure of the relative importance of this interaction in a given powder. The bulk density of powder is good for packaging of the tablets. Carr's index was found to be below $16 \%$ for all formulations, which indicated acceptable flow properties. Hausner's ratio for all formulations was less than $2 \%$ which also indicated the good flow property of the powders. Angle of repose showed that the flow property of the powder was good and it was within acceptable limits. 


\section{Characterization of Abacavir sulphate effervescent floating tablets}

The average weight of tablets was found to be in the range of 296 to $299 \mathrm{mg}$ and friability was found to be 0.42 to $0.60 \%$. The thickness was found to be 2.68 to $3.90 \mathrm{~mm}$. The evaluation results show that all the parameters were within acceptable limits. Individual readings of all formulations were tabulated in Table -3 .

Table - 2: Pre-compression studies of formulations

\begin{tabular}{ccccccc}
\hline S. No. & Parameters & $\begin{array}{c}\text { Bulk } \\
\text { density }\end{array}$ & $\begin{array}{c}\text { Tapped } \\
\text { density }\end{array}$ & $\begin{array}{c}\text { Carr's } \\
\text { index }\end{array}$ & $\begin{array}{c}\text { Angle of } \\
\text { repose }\end{array}$ & $\begin{array}{c}\text { Hausner's } \\
\text { ratio }\end{array}$ \\
\hline $\mathbf{1}$ & $\mathbf{F 1}$ & 0.456 & 0.554 & 11.9 & 27.7 & 1.14 \\
$\mathbf{2}$ & $\mathbf{F 2}$ & 0.456 & 0.527 & 15 & 26.4 & 1.12 \\
$\mathbf{3}$ & $\mathbf{F 3}$ & 0.452 & 0.560 & 12.4 & 29.2 & 1.18 \\
$\mathbf{5}$ & $\mathbf{F 4}$ & 0.458 & 0.572 & 15.3 & 28.4 & 1.16 \\
$\mathbf{6}$ & $\mathbf{F 5}$ & 0.461 & 0.583 & 12.2 & 29.5 & 1.15 \\
$\mathbf{7}$ & $\mathbf{F 6}$ & 0.434 & 0.575 & 11.2 & 28.4 & 1.18 \\
$\mathbf{8}$ & $\mathbf{F 7}$ & 0.455 & 0.528 & 13.6 & 29.8 & 1.08 \\
$\mathbf{9}$ & $\mathbf{F 8}$ & 0.460 & 0.531 & 12.2 & 27.5 & 1.18 \\
\hline
\end{tabular}

\section{Drug content}

The drug content for various formulations was found to be in the range of $67.6 \%$ to 97.8 which is shown in Table - 3.

Table - 3:Standard physical test for Abacavir sulphate effervescent floating tablet

\begin{tabular}{cccccc}
\hline Formulations & $\begin{array}{l}\text { Thickness } \\
(\mathbf{m m})\end{array}$ & $\begin{array}{l}\text { Hardness } \\
\left(\mathbf{k g} / \mathbf{c m}^{2}\right)\end{array}$ & $\begin{array}{l}\text { Weight } \\
\text { variation } \\
(\mathbf{m g})\end{array}$ & $\begin{array}{l}\text { Friability } \\
(\boldsymbol{\%})\end{array}$ & $\begin{array}{l}\text { Content } \\
\text { uniformity } \\
(\boldsymbol{\%})\end{array}$ \\
\hline F1 & 3.80 & 4.7 & 298 & 0.60 & $88.4 \%$ \\
F2 & 3.90 & 5.2 & 296 & 0.51 & $67.6 \%$ \\
F3 & 3.79 & 5.1 & 296 & 0.54 & $69.2 \%$ \\
F4 & 3.68 & 5.3 & 299 & 0.52 & $89.3 \%$ \\
F5 & 3.73 & 5.4 & 297 & 0.53 & $68.5 \%$ \\
F6 & 3.62 & 5.5 & 297 & 0.48 & $78.4 \%$ \\
F7 & 2.75 & 5.6 & 299 & 0.42 & $92.1 \%$ \\
F8 & 2.68 & 5.3 & 298 & 0.51 & $88.4 \%$ \\
F9 & 2.74 & 5.7 & 299 & 0.45 & $97.8 \%$ \\
\hline
\end{tabular}

In-Vitro Buoyancy Studies: Sodium bicarbonate was used along with citric acid in the formulation as gas generating agent in contact with acidic aqueous media $\mathrm{CO}_{2}$ is generated. The observations of all formulations were tabulated in Table 4. 
Table - 4: Floating capacity of all formulations

\begin{tabular}{ccc}
\hline Formulations & $\begin{array}{l}\text { Floating lag time } \\
\text { (sec) }\end{array}$ & $\begin{array}{l}\text { Total floating } \\
\text { time (hours) }\end{array}$ \\
\hline F1 & 95 & $>3$ \\
F2 & 40 & $>2$ \\
F3 & 70 & $>2$ \\
F4 & 85 & $>4$ \\
F5 & 60 & $>2$ \\
F6 & 70 & $>3$ \\
F7 & 95 & $>5$ \\
F8 & 70 & $>3$ \\
F9 & 95 & $>6$ \\
\hline
\end{tabular}

\section{Swelling index}

Swelling studies revealed that the F-9 formulation showed more swelling in $0.1 \mathrm{~N}$ $\mathrm{HCl}$ because of its gelling properties of Carbopol 974P and Ethyl cellulose was observed as $98.35 \%$, has attained a sustained release pattern. A comparative value for formulations F-1 to F-9 is shown in Table 5 and fig 5.

\begin{tabular}{ccccc}
\multicolumn{5}{c}{ Table - 5: \% swelling index of formulated batches } \\
\hline \multirow{2}{*}{ Batch } & \multicolumn{4}{c}{ Time (hrs) } \\
\cline { 2 - 5 } & $\mathbf{1}$ & $\mathbf{2}$ & $\mathbf{4}$ & $\mathbf{6}$ \\
\hline F1 & 18.55 & 32.25 & 47.68 & 61.24 \\
F2 & 22.18 & 44.56 & 55.89 & 66.35 \\
F3 & 30.64 & 48.25 & 58.12 & 70.43 \\
F4 & 32.55 & 53.76 & 65.89 & 76.14 \\
F5 & 40.79 & 60.43 & 67.79 & 80.46 \\
F6 & 47.94 & 63.52 & 73.24 & 89.56 \\
F7 & 51.10 & 65.18 & 77.68 & 92.87 \\
F8 & 56.75 & 66.55 & 77.98 & 94.66 \\
F9 & 76.77 & 78.10 & 87.09 & 98.35 \\
\hline
\end{tabular}

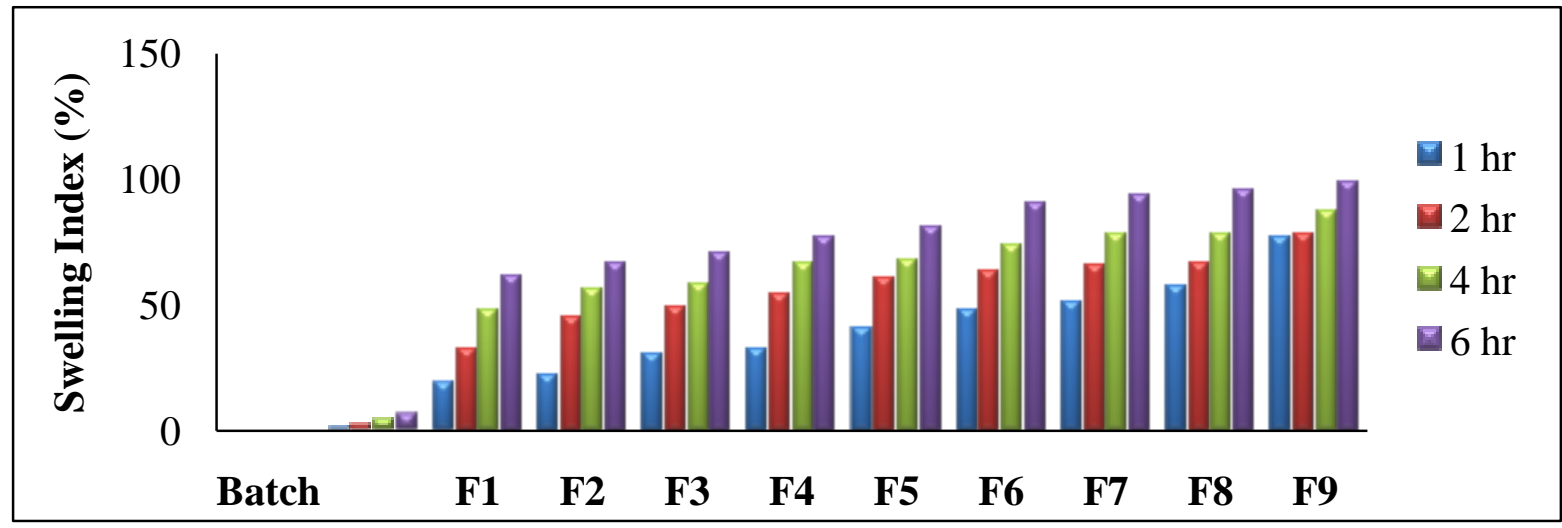

Fig - 5: \% Swelling Index 


\section{In-Vitro Drug Release Studies}

The in-vitro drug release characteristics were studied in $0.1 \mathrm{~N} \mathrm{HCl}$ for 7 hours under sink condition using USP dissolution apparatus type II, employing paddle stirrer at 50 RPM and $900 \mathrm{ml}$ of $0.1 \mathrm{~N} \mathrm{HCl}$ of $\mathrm{pH} 1.2$ as dissolution medium, the in-vitro dissolution data of all the designed formulations are shown and dissolution profiles were kept in the following table 6 and graph in fig 6.

Table 6: \%Release pattern of drug from all formulations

\begin{tabular}{|c|c|c|c|c|c|c|c|c|c|}
\hline \multirow{2}{*}{$\begin{array}{l}\text { Time } \\
\text { (hrs) }\end{array}$} & \multicolumn{9}{|c|}{ \% Drug Release } \\
\hline & F1 & F2 & F3 & F4 & F5 & F6 & F7 & F8 & F9 \\
\hline 0 & 0 & 0 & 0 & 0 & 0 & 0 & 0 & 0 & 0 \\
\hline 0.5 & 7.9 & 6.9 & 6.31 & 8.23 & 7.2 & 8.12 & 8.96 & 9.23 & 10.75 \\
\hline 1 & 8.73 & 7.5 & 8.11 & 9.56 & 8.23 & 9.56 & 10.36 & 12.85 & 18.69 \\
\hline 1.5 & 13.65 & 11.51 & 10.36 & 15.42 & 14.32 & 17.23 & 21.23 & 23.5 & 29.98 \\
\hline 2 & 19.74 & 16.75 & 16.36 & 22.36 & 19.62 & 23.85 & 29.56 & 32.69 & 44.21 \\
\hline 2.5 & 28.45 & 25.54 & 24.81 & 35.23 & 29.85 & 36.23 & 42.7 & 48.39 & 58.23 \\
\hline 3 & 37.42 & 36.84 & 28.65 & 45.63 & 40.65 & 45.23 & 51.65 & 59.65 & 67.69 \\
\hline 4 & 46.52 & 43.25 & 39.85 & 56.31 & 49.65 & 57.68 & 63.75 & 67.56 & 79.56 \\
\hline 5 & 55.32 & 50.61 & 46.23 & 66.21 & 56.23 & 69.12 & 71.56 & 75.56 & 87.23 \\
\hline 6 & 61.05 & - & 53.45 & 74.23 & 62.58 & - & 79.62 & - & 90.56 \\
\hline 7 & 72.58 & - & - & 77.25 & - & - & 82.32 & - & 87.23 \\
\hline
\end{tabular}

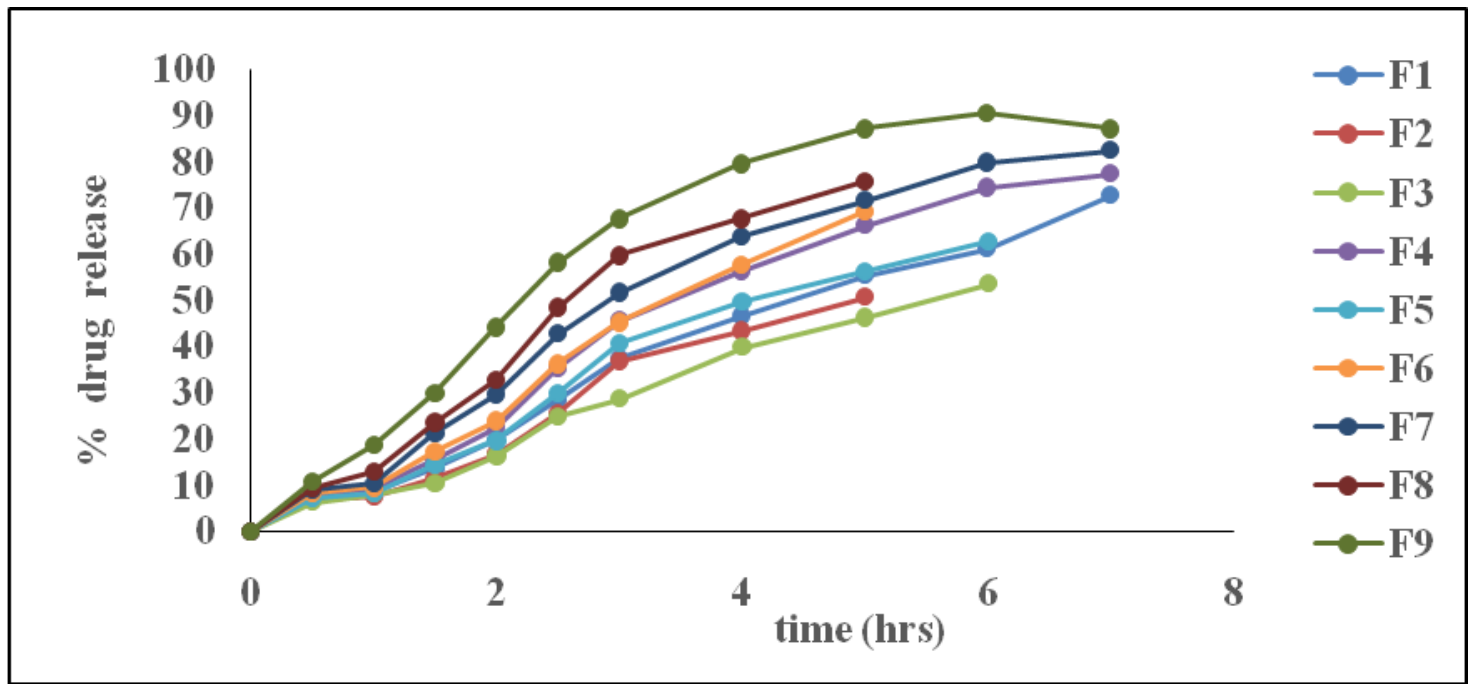

Fig - 6: \% release pattern of drug from all formulations 


\section{Drug Release Kinetics}

The coefficient of regression and release constant values of Korsmeyer - Peppas model was found that the release of Abacavir sulphate effervescent floating tablets follows Korsmeyer- Peppas kinetics.

Table - 7: Release kinetics data of different model for optimized formulation (F9)

\begin{tabular}{lccccc}
\hline $\begin{array}{l}\text { Formulation } \\
\text { code }\end{array}$ & $\begin{array}{c}\text { Zero } \\
\text { order }\end{array}$ & First order & $\begin{array}{c}\text { Higuchi } \\
\text { kinetics }\end{array}$ & $\begin{array}{c}\text { Korsmeyer - Peppas } \\
\left(\mathbf{t}_{60} \%\right)\end{array}$ \\
\hline \multirow{2}{*}{ F9 } & $\mathbf{R}^{\mathbf{2}}$ & $\mathbf{R}^{\mathbf{2}}$ & $\mathbf{R}^{\mathbf{2}}$ & $\mathbf{n}$ & $\mathbf{R}^{\mathbf{2}}$ \\
\cline { 2 - 6 } & 0.8833 & 0.5509 & 0.9373 & 1.1677 & 0.9959 \\
\hline
\end{tabular}

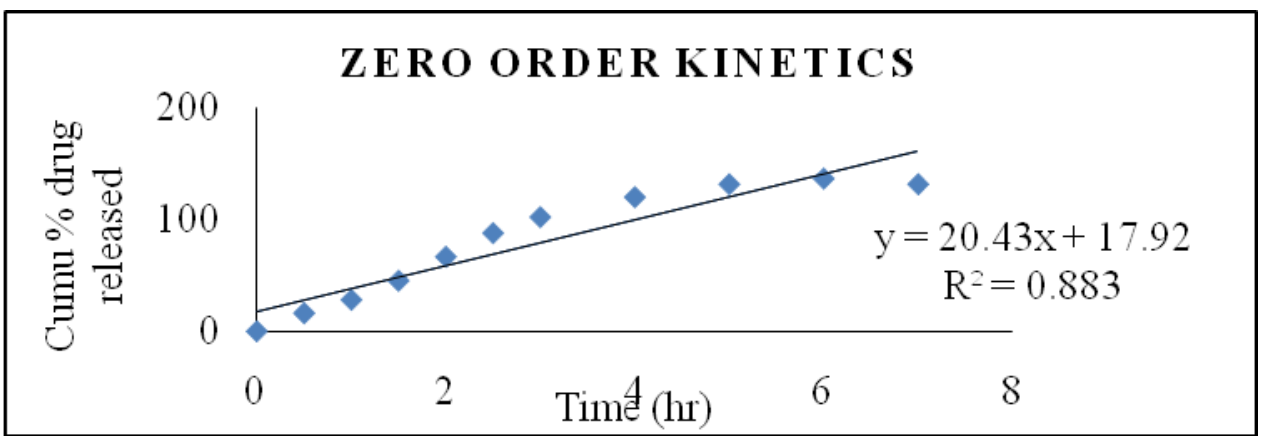

Fig -7: Plot of cumulative \% drug release vs. time of optimized formulation (F9)

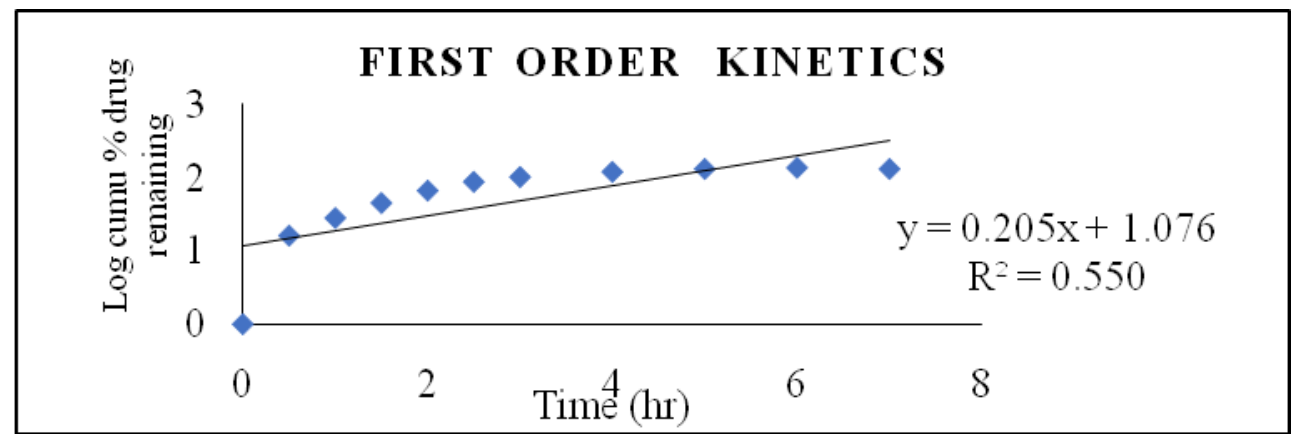

Fig - 8: Plot of log cumulative \% drug retained vs. time of optimized formulation (F9)

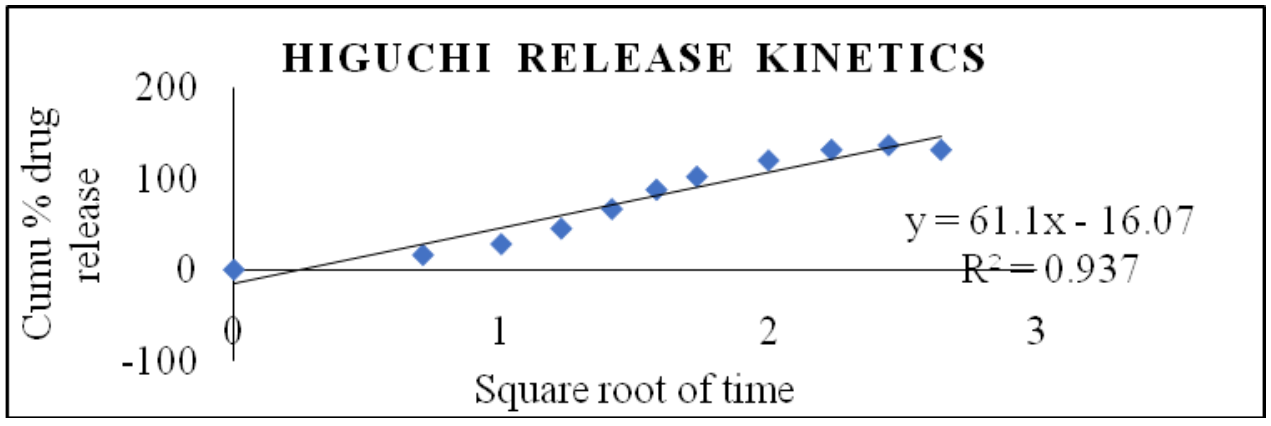

Fig - 9: Plot of cumulative \% drug released vs. root time of optimized formulation (F9) 


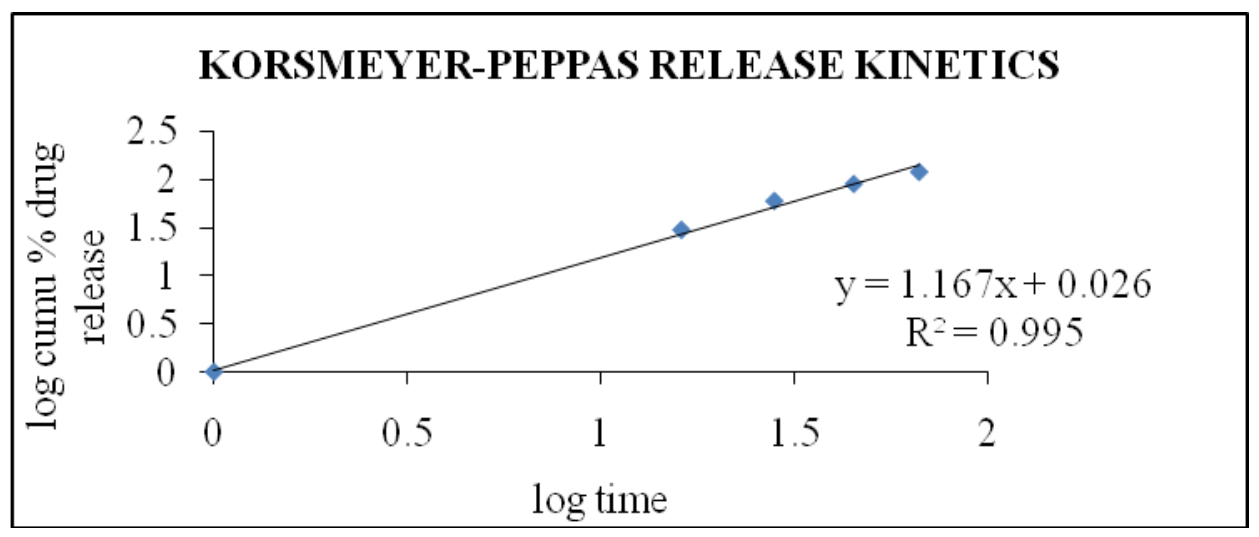

Fig - 10: Plot of log cumulative \% drug released vs. log time of optimized formulation (F9)

\section{CONCLUSION}

The prepared effervescent floating tablets were subjected to various pharmaceutical parameters such as bulk density, tapped density, angle of repose, weight variation, thickness, hardness and friability. The results indicated that the parameters drug content, swelling index, in-vitro drug release studies and in-vitro buoyancy studies are within Pharmacopeia limits. The optimized formulation (F9) shows the hardness of $5.7 \mathrm{~kg} / \mathrm{cm}^{2}$, tablet thickness of $2.74 \mathrm{~mm}, 0.45 \%$ of friability, in-vitro buoyancy was up to 6 hours and \% drug release was $90.56 \%$ in 6 hours. These studies revealed that all the parameters are within the range of acceptable limits for the effervescent floating tablets. Drug release kinetics was found that it follows the Korsmeyer - Peppas equation.FT-IR and DSC studies confirmed that there was no interaction between Abacavir sulphate and other ingredients used in the tablet formulations. In which (F9) formulation has showed sustained in-vitro drug release, and also good swelling, floating lag time and follows Korsmeyer-peppas kinetics. Hence, it is concluded that F9 formulation (Drug, Carbopol 974P and Ethyl Cellulose) of effervescent floating tablet shows sustained action to $6 \mathrm{hrs}$.

\section{DECLARATION OF INTEREST}

The authors report no conflicts of interest. The authors are responsible for the content and writing of this paper.

\section{ACKNOWLEDGEMENT}

The authors are thankful to the management of Nalla Narasimha Reddy Educational Society's Group of Institutions for providing the laboratory facilities to carry out the research work.

\section{REFERENCE}

[1] A. Kumar, A. Verma, G. Sharma, R. Saini, S. Sharma, Formulation and Characterization of Effervescent Floating Matrix Tablets of Famotidine Hydrochloride, Asian Journal of Biomedical and Pharmaceutical Sciences. 03 (2013) 43-47.

[2] C. Shashank, K. Prabha, S. Sunil, A.V. Kumar, Approaches to Increase The Gastric 
Residence Time: Floating Drug Delivery Systems- A Review, Asian Journal of Pharmaceutical and Clinical Research. 6 (2013) 1-9.

[3] B.J. R.Margret Chandira, P.Palanisamy, Formulation and Evaluation of Bilayered Floating Tablets of Metformin Hydrochloride, International Research Journal of Pharmacy. 3 (2012) 257-266.

[4] K.P.N. Gulhane, ISSN 2277 - 7202 Original Article Floating Drug Delivery System ( Fdds ): A New Way for Oral, International Journal. 3 (2013) 1-13.

[5] P.K. N. G. Raghavendra Rao, Sunil Firangi, Formulation and Evaluation of Gastroretentive Effervescent Floating Drug Delivery System of Zidovudine, American Journal of PharmTech Research. 2 (2012) 513-529.

[6] P.J.S.. Dalavi V.V, Gastroretentive drug delivery system of an antiretroviral agent, International Journal of PharmTech Research. 1 (2009) 1678-1684.

[7] J.H. Page, P. Hyma, D. Yashwanth, S. Prasad, International Journal of Current Trends in Pharmaceutical Research Open Access Development and characterization of floating matrix tablets of Abacavir sulphate using natural polymers, 4 (2016) 192196.

[8] S.G.L. Bihani, S.D. College, T. Education, P. Sciences, I, Journal of Drug Delivery \& Therapeutics. 2 (2011) 18-24.

[9] A. Sarawade, M.P. Ratnaparkhi, S. Chaudhari, Floating drug delivery system: an overview., International Journal of Research and Development in Pharmacy \& Life Sciences. 3 (2014) 1106-1115.

[10] A. Chandel, K. Chauhan, B. Parashar, H. Kumar, S. Arora, Floating drug delivery systems: A better approach, International Current Pharmaceutical Journal. 1 (2012) 119-127.

[11] J. Nair, Binoy.B, Jayachandran Nair C.V, Floating drug delivery system- a new approach in gastric retention- a review, A Journal of drug delivery, volume 1, issue 3, 2012, page no:18. 